\title{
Desain Jaringan Distribusi Bantuan Sosial Beras Sejahtera (Bansos Rastra) menggunakan Metode Distribution Requirement Planning
}

\author{
Fiqri Himawan ${ }^{\# 1}$, Eva Faja Ripanti ${ }^{* 2}$, Nurul Mutiah ${ }^{\# 3}$

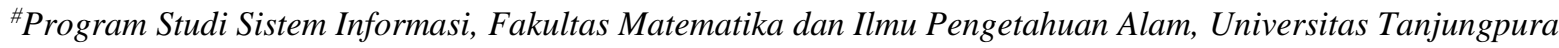 \\ Jl. Prof. Dr. H. Hadari Nawawi, Pontianak \\ ${ }^{1}$ fiqrihimawan@gmail.com \\ ${ }^{3}$ nurulesisfo.untan.ac.id \\ *Program Studi Informatika, Fakultas Teknik, Universitas Tanjungpura \\ Jl. Prof. Dr. H. Hadari Nawawi, Pontianak \\ ${ }^{2}$ evaripanti@untan.ac.id
}

\begin{abstract}
Abstrak- Desain jaringan distribusi merupakan bagian Supply Chain Management (SCM) untuk mengoptimalkan jaringan distribusi agar terhindar dari kelebihan atau kekurangan inventory. Penelitian ini dilakukan pada Perum BULOG Divisi Regional Kalimantan Barat dengan mengadopsi konsep Distribution Requirement Planning (DRP) yang berfokus kepada inventory dan saluran distribusi. Tujuan penelitian ini adalah mendesain jaringan distribusi Bantuan Sosial Beras Sejahtera (Bansos Rastra) yang dapat digunakan sebagai pedoman untuk mengoptimalkan sistem distribusi sehingga memberikan layanan terbaik kepada masyarakat. Metodologi penelitian yang dilakukan yaitu pengumpulan data, menganalisis kebutuhan, perancangan dan implementasi. pengumpulan data melalui studi literatur, wawancara dan observasi. Analisis dan Perancangan dilakukan dengan pendekatan System Development Life Cycle (SDLC) yang diilustrasikan dalam bentuk Unified Modelling Language (UML) berupa class diagram. Pengujian dilakukan dengan cara User Acceptance Testing (UAT) dengan teknik indepth interview. Hasil pengujian model jaringan distribusi Bansos Rastra dapat diterapkan pada Perum BULOG Divre Kalbar. Secara keseluruhan, desain jaringan distribusi dapat membantu mengoptimalkan jaringan distribusi agar lebih efisien.
\end{abstract}

Kata kunci - Distribution Requirement Planning, Jaringan Distribusi, Perum BULOG, SDLC, Supply Chain Management

\section{Pendahuluan}

Jaringan distribusi adalah satu relasi antar entitas dalam hal ini berperan sebagai perangkat distribusi untuk memenuhi kebutuhan konsumen. Jaringan distribusi dapat digambarkan berupa koneksi antar tempat sesuai dengan posisi tempat tersebut. Entitas yang terlibat pada jaringan distribusi dapat meliputi mulai dari supplier ke end user yang melibatkan warehouse, inventory, store retailer dan customer [1][2][3]. Desain jaringan distribusi dapat dioptimalkan dengan berbagai metode yang sesuai salah satunya metode Distribution Requirement Planning (DRP). Metode ini adalah sebuah strategi untuk mengoptimalkan perencanaan terkait distribusi sehingga inventory dapat memenuhi kebutuhan tertentu. Metode ini juga dilakukan untuk memenuhi demand pada suatu item fasilitas saluran distribusi [4][5].

Jaringan distribusi merupakan suatu perancangan yang penting dalam sebuah organisasi agar dapat membantu perencanaan dan implementasi pemenuhan kebutuhan konsumen sehingga dapat mengoptimalkan layanan setiap organisasi tersebut. Perum BULOG adalah salah satu Badan Usaha Milik Negara (BUMN) yang saat ini memiliki tugas dan fungsi dalam urusan logistik. Bantuan Sosial Beras Sejahtera (Bansos Rastra) adalah salah satu Program dari Perum BULOG untuk memenuhi kebutuhan beras pada masyarakat pra sejahtera. Pada penelitian fokus pada Perum BULOG Divre Kalbar.

Saat ini Perum BULOG tentunya telah memiliki sebuah jaringan distribusi untuk Program Bansos Rastra. Namun langkah optimalisasi perlu dilakukan misalnya dengan melakukan perbaikan perencanaan dengan mengimplementasikan metode-metode tertentu seperti Distribution Requirement Planning (DRP). Penelitian ini bertujuan untuk menghasilkan sebuah jaringan distribusi untuk Bansos Rastra dengan metode DRP. Jaringan distribusi tersebut dapat dijadikan pedoman dalam mengimplementasikan sistem distribusi mulai dari supplier ke masyarakat penerima Bansos Rastra atau customer. Studi lebih lanjut dilakukan antara lain mengidentifikasi sistem distribusi Perum BULOG saat ini, khususnya Bansos Rastra, dimana hal ini dilakukan untuk membangun desain distribusi itu sendiri. Analisis dan perancangan juga dilakukan dengan pendekatan System Development Life Cycle (SDLC) untuk memperkuat analisis jaringan distribusi juga untuk menghasilkan sebuah model atau sistem informasi jaringan distribusi Bansos Rastra. 
Tujuan dari penelitian ini adalah mendesain jaringan distribusi Bantuan Sosial Beras Sejahtera (Bansos Rastra) dengan metode Distribution Requirement Planning (DRP). Adapun sasaran penelitian sebagai berikut:

1. Identifikasi proses supply chain Bansos Rastra pada Perum BULOG Divre Kalbar.

2. Analisis kebutuhan Bansos Rastra pada Perum BULOG Divre Kalbar.

3. Merancang jaringan distribusi Bansos Rastra pada Perum BULOG Divre Kalbar.

4. Memvalidasi jaringan distribusi Bansos Rastra pada Perum BULOG Divre Kalbar.

\section{KAJIAN PUSTAKA}

\section{A. Perum BULOG}

Perum BULOG memiliki kebijakan beras Nasional yang diatur di dalam Intruksi Presiden (Inpres) [6] Republik Indonesia Nomor 5 Tahun 2015 Tentang Kebijakan Gabah/Beras dan Penyaluran Beras oleh Pemerintah. Program Bantuan Sosial Beras Sejahtera (Bansos Rastra) merupakan implementasi dari Inpres No 5 Tahun 2015. Tujuan Program Bansos Rastra untuk mengurangi pengeluaran dari Keluarga Penerima Manfaat (KPM) dengan memenuhi kebutuhan pangan beras. Bantuan berupa beras berkualitas medium dengan jumlah sebanyak $10 \mathrm{~kg}$ setiap bulannya tanpa dikenakan harga/biaya tebus

\section{B. Supply Chain Management}

Supply Chain Management (SCM) [5] meliputi perencanaan dan manajemen semua kegiatan yang terlibat di dalam sourcing dan procurement, konversi dan semua aktivitas manajemen logistik. Tujuan dari SCM untuk memaksimalkan nilai keseluruhan yang dihasilkan untuk memenuhi kebutuhan dan permintaan pelanggan [7]. Tipikal supply chain melibatkan berbagai tahap, baik langsung maupun tidak langsung. Terdapat 5 tahapan di dalam supply chain seperti pada Gambar 1 .

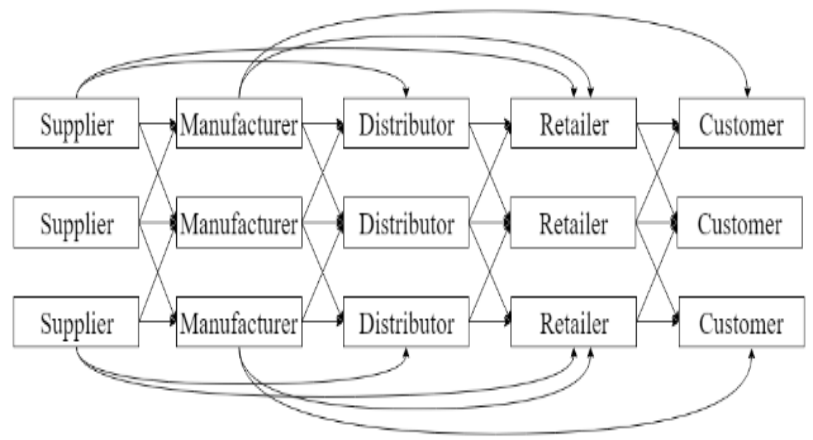

Gambar. 1 Tahapan supply chain

\section{Jaringan Distribusi}

Jaringan distribusi [1] adalah interkoneksi dari tempat distribusi oleh perangkat distribusi untuk memenuhi demand customer. Sedangkan [2] Jaringan distribusi adalah sistem perantara antara supplier produk dan end user. Faktor yang mempengaruhi jaringan distribusi terbagi menjadi dua bagian, yaitu kebutuhan pelanggan yang terpenuhi dan biaya memenuhi kebutuhan pelanggan [7]. komponen kebutuhan pelanggan kebutuhan pelanggan yang terpenuhi adalah response time, product variety, product availability, customer experience, returnability, time to market dan order visibility. Sementara komponen biaya memenuhi kebutuhan pelanggan adalah inventory, transportation, facility dan handling, dan information.

\section{Distribution Requirement Planning}

Distribution Requirement Planning (DRP) [5] adalah menentukan kebutuhan inventory berdasarkan timephasing supply untuk memenuhi demand pada setiap item disetiap fasilitas saluran distribusi. Memanfaatkan logika terkomputerisasi yang sama dengan Material Requirement Planning (MRP), DRP mengkompilasikan penambahan inventory yang dibutuhkan pada setiap fasilitas pada saluran yang keluar melalui perencanaan secara horizon. Ketika demand melebihi dari supply yang tersedia, sistem menghasilkan rencana pesanan untuk resupply dan diperlukan tindakan pengisian ulang untuk menghindari kekosongan stok.

Komponen-komponen DRP [5] terdiri dari analisis sistem push dan pull, analisis Bill Of Distribution (BOD), forecasting, safety stock dan lot size. Sedangkan informasi pendukung pada metode DRP adalah lead time, inventory on hand.

TABEL I

DRP WORKSHEET

\begin{tabular}{|c|c|c|c|c|c|}
\hline Product & & & & & \\
\hline Safety Stock & & & & & \\
\hline Order Quantity & & & & & \\
\hline Lead Time & & & & & \\
\hline On Hand & & 3 & 4 & 5 & 6 \\
\hline Gross Requirem & & & & & \\
\hline DRP instransit $F$ & & & & & \\
\hline Projected Availa & Balance & & & & \\
\hline Net Requiremen & & & & & \\
\hline DRP Planned OI & - Receipts & & & & \\
\hline DRP Planned OI & Release & & & & \\
\hline
\end{tabular}

\section{E. System Development Life Cycle}

Sistem informasi adalah kumpulan komponen yang saling terkait dimana terdapat terdapat beberapa aktivitas mengumpulkan, memproses, menyimpan, dan mendistribusikan informasi. Sistem informasi juga mendukung pengambilan keputusan, koordinasi, kontrol, analisis masalah dan menciptakan produk baru Memberikan solusi terhadap tantangan di lingkungan bisnis [8][9][10].

SDLC dijelaskan sebagai proses memahami bagaimana suatu sistem informasi dapat mendukung kebutuhan bisnis dengan merancang suatu sistem, membangunnya, dan mengirimkannya kepada pengguna [11]. Sementara alat yang digunakan untuk melakukan analisis dan desain dapat menggunakan analisis dan desain berorientasi objek 
dengan tool unified modeling language (UML). UML adalah bahasa standar untuk menulis blueprint software yang dapat digunakan untuk memvisualisasikan, menspesifikan, membangun dan mendokumentasikan [12]

\section{F. User Acceptance Testing}

User Acceptance Testing (UAT) [13] adalah memastikan produk akhir mendukung dari kebutuhan pengguna. Untuk bisnis aplikasi, ini berarti menguji bahwa sistem memungkinkan pengguna untuk melakukan bisnis dengan benar dan efisien. Pada pelaksanaan user acceptance testing dilakukan beberapa tahapan, menurut [14] kegiatan pengujian perlu direncanakan sehingga berjalan dengan efektif.

\section{METODOLOGI PENELITIAN}

Pada penelitian ini metodologi penelitian berdasarkan kerangka kerja IS research [15]. Pemodelan pada kerangka kerja IS Research diterjemahkan dalam beberapa tahapan yang diikuti metode sehingga gambaran dari masingmasing tahapannya dapat direncanakan menyamakan setiap tahapan di dalam IS research. Langkah-langkah penelitian terdiri dari pengumpulan data, analisis kebutuhan, perancangan dan implementasi. Dukungan lain bersumber dari environtment dan knowledge base. Adapun metodologi penelitian desain jaringan distribusi menggunakan metode Distribution Requirement Planning (DRP) terdapat pada Gambar 2.

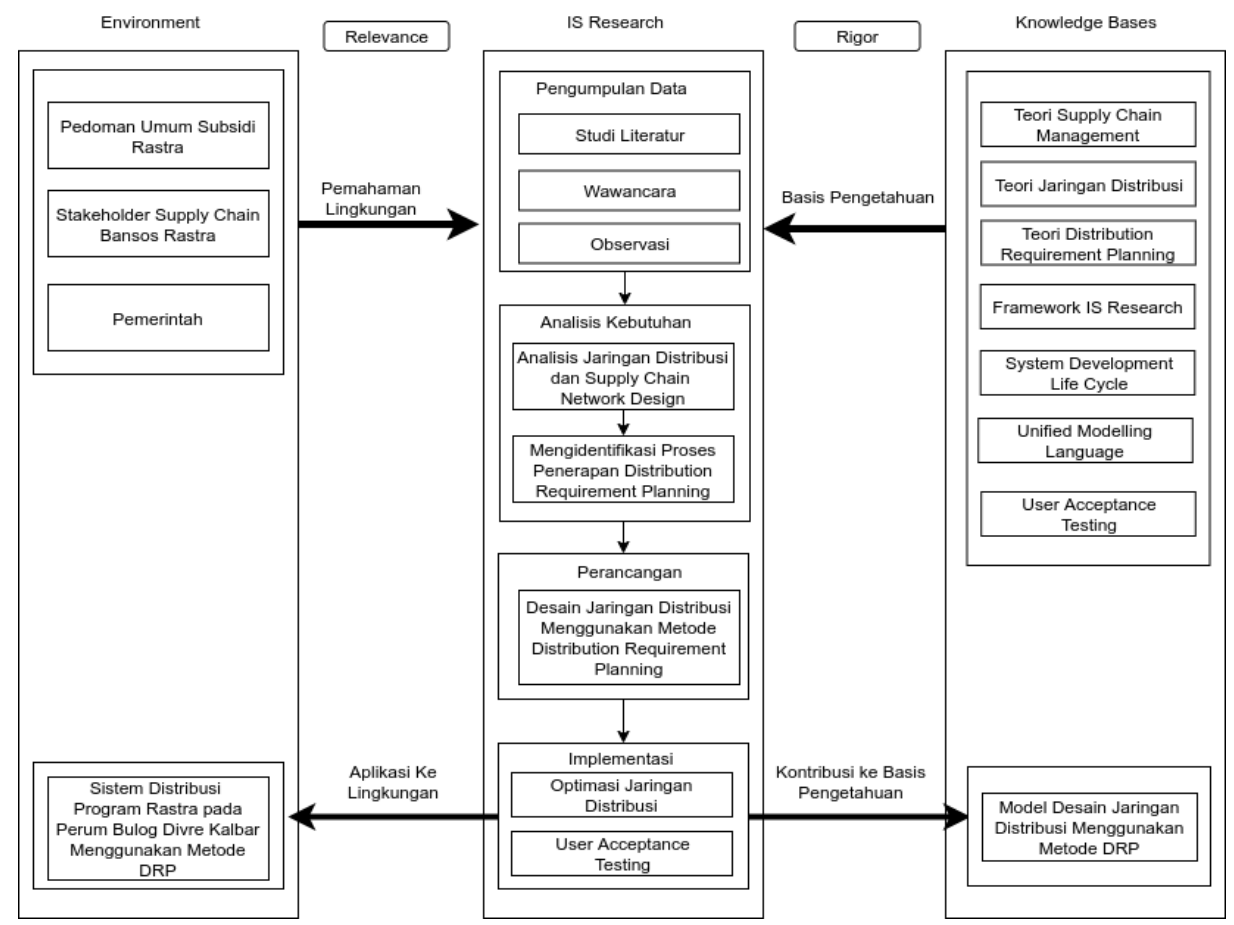

Gambar. 2 Metodologi penelitian

\section{HASIL DAN PEMBAHASAN}

Model jaringan distribusi Bansos Rastra yang dihasilkan dapat diilustrasikan pada Gambar 3. proses distribusi Bansos Rastra pada Perum BULOG belum mengadopsi Distribution Requirement Planning (DRP). Model tersebut menjelaskan pada aktivitas distribusi Bansos Rastra pada Perum BULOG terdiri dari lima bagian utama yang terlibat yaitu gudang, JPLogistik, Kementerian Sosial, Pemerintah Daerah, Keluarga Penerima Manfaat (KPM). Bagian-bagian tersebut melakukan beberapa aktifitas penting mulai dari penyimpanan, pengolahan, transportasi, distribusi, pemeriksaan. Jaringan distribusi Bansos Rastra pada Perum BULOG terlihat telah memiliki desain distribusi yang sesuai dengan kebutuhan Perum BULOG. Informasi yang didapat melalui tahap wawancara bahwa desain distribusi tersebut dibuat oleh Perum BULOG sehingga Perum BULOG Divre Kalbar hanya perlu melakukan koordinasi dari pedoman atau desain yang telah ditetapkan

Implementasi DRP pada model jaringan distribusi ini fokus pada dua hal utama yaitu inventory dan saluran distribusi. Tujuan dari pengadopsian DRP ini adalah untuk mengoptimalkan jaringan distribusi pada Bansos Rastra Perum BULOG Divre Kalbar. Inventory dan saluran distribusi kemudian di analisis sehingga diketahui berdasarkan 5 komponen DRP, bahwa untuk penelitian ini hanya tepat diimplementasikan untuk 3 komponen yaitu push dan pull, Bill of Distribution (BOD) dan lot size. Dari analisis tersebut dapat membutuhkan response time, product availability, customer experience, returnability, order visibility. 


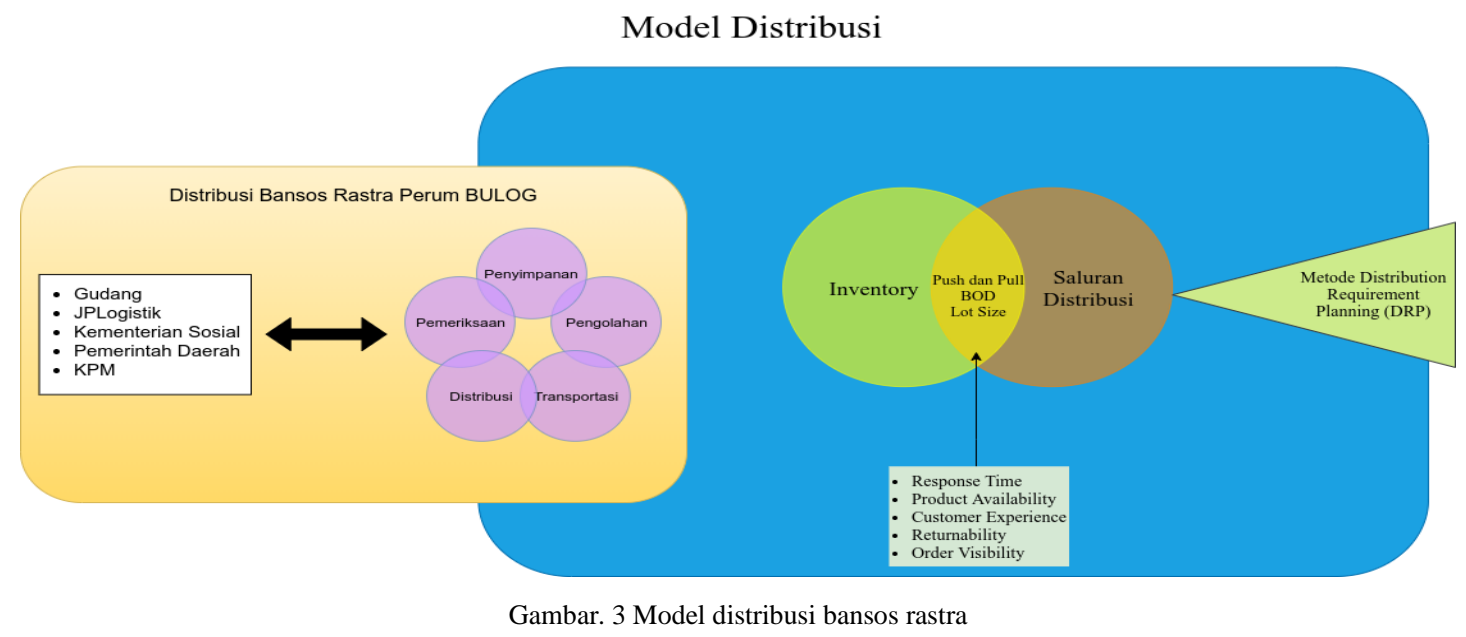

\section{A. Desain Supply Chain Bansos Rastra}

Berdasarkan kondisi yang ada di Perum BULOG Divre Kalbar maka dapat dijelaskan alur supply chain Bansos Rastra seperti pada Gambar 4.

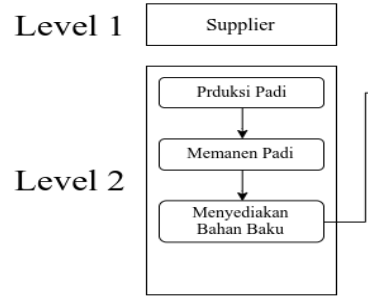

Level 3

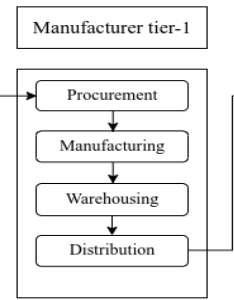

Perum BULOG

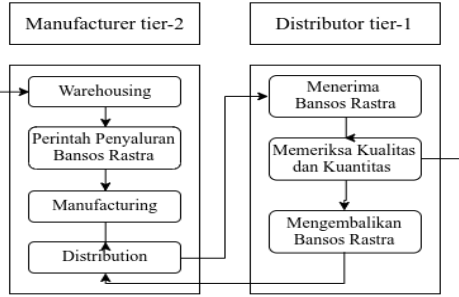

\begin{tabular}{|c|}
\hline Pelaksana Distribusi \\
Titik Distribusi \\
\hline
\end{tabular}
Berdasarkan Gambar tersebut supply chain Bansos Rastra pada Perum BULOG Divre Kalbar terbagi menjadi tiga level, adapun peran masing-masing sebagai berikut:

Gambar. 4 Supply chain bansos rastra

1) Supplier: Memiliki peran sebagai penyedia bahan baku. melakukan aktivitas antara lain memproduksi padi hingga proses panen. Aktor dari supplier adalah kemitraan yang terdiri dari Mitra Kerja Pengadaan dan Onfarm.

2) Manufacturer Tier-1: Pada tahap ini bahan baku melewati proses produksi menjadi produk setengah jadi. Aktivitas diantara lain melakukan procurement bahan baku, kemudian akan dilakukan proses manufacturing. Aktor dari manufacturer tier-1 adalah Perum BULOG.

3) Manufacturer Tier-2: Berperan mengelola dari bahan setengah jadi menjadi produk akhir. melakukan aktivitas diantara lain warehousing. Setelahnya mendapatkan perintah untuk penyaluran Bansos Rastra, terlebih dahulu akan di proses manufacturing dengan melakukan pengemasan ulang beras $50 \mathrm{Kg}$ menjadi produk akhir dengan kuantitas $10 \mathrm{Kg}$. Setelahnya produk akan dilakukan proses distribution. Aktor yang berperan adalah Perum BULOG Divre Kalbar dibantu oleh Perum BULOG Subdivre dan Perum BULOG Kansilog.

4) Distributor Tier-1: Berperan sebagai lokasi untuk mengirimkan Bansos Rastra untuk dilakukan pengecekan. Aktivitas melakukan penerimaan produk, kemudian akan dilakukan pengecekan kuantitas dan kualitas. Proses tersebut akan mendapatkan 2 hasil yaitu diterima dan ditolak. Apabila diterima akan dilanjutkan ketahap selanjutnya, sedangkan Bansos Rastra yang ditolak akan dikembalikan. Aktor merupakan Pelaksana Distribusi Titik Distribusi dari Program Bansos Rastra yang telah ditetapkan.

5) Distributor Tier-2: Sebagai lokasi untuk memenuhi permintaan. Melakukan aktivitas pembagian Bansos Rastra sesuai Daftar Penerima Manfaat (DPM). Aktor yang berperan adalah Pelaksana Distribusi Titik Bagi

6) Customer: Berperan sebagai end user dimana produk telah sampai kepada customer. Aktivitas pihak customer menerima Bansos Rastra dengan ukuran kuantitas sebesar $10 \mathrm{Kg}$, setelahnya produk yang diterima akan dikonsumsi. Aktor yang berperan pada tahapan ini adalah Keluarga Penerima Manfaat (KPM).

\section{B. Desain Jaringan Distribusi}

Mendesain sebuah jaringan distribusi melewati dua tahapan yaitu analisis kebutuhan dan keputusan desain jaringan supply chain. Dalam menganalisis dibutuhkan metode untuk mengetahui bagaimana kinerja dari jaringan distribusi dan strategi yang diterapkan oleh Perum BULOG Divre Kalbar. analisis dilakukan berdasarkan 2 
dimensi yaitu kebutuhan pelanggan yang terpenuhi dan biaya dalam memenuhi kebutuhan pelanggan.

Analisis dilakukan untuk mengetahui kemampuan dalam menjalankan Program Bansos Rastra. Adapun hasil analisis kebutuhan pelanggan diantara lain:

1) Response Time: Perum BULOG merespon dengan baik apabila terdapat perintah untuk menyalurkan Bansos Rastra pada Titik Distribusi. Waktu yang dibutuhkan Perum BULOG Divre Kalbar untuk mendistribusikan Bansos Rastra hingga Titik Distribusi selama \pm 1 hari. Namun tidak semua wilayah mendapatkan Bansos Rastra setiap bulannya.

2) Product Availability: Perum Bulog Divre Kalbar menjaga stok beras agar tetap tersedia untuk mengantisipasi lonjakan harga beras atau kelangkaan beras. Ketersediaan Beras juga untuk menjalankan fungsi untuk mendistribusikan beras pada masyarakat golongan tertentu yaitu Bansos Rastra.

3) Customer Experience: Bansos Rastra yang didistribusikan pada KPM melewati Titik Bagi tidak dikenakan biaya, lokasi Titik Bagi yang strategis juga membantu untuk KPM lebih mudah dan meminimalkan biaya transportasi KPM menuju Titik Bagi.

4) Order Visibility: Distribusi Bansos Rastra yang dilakukan pada Titik Distribusi sudah terjalin kerja sama dalam hal waktu dan lokasi penyerahan. Proses transportasi menggunakan jasa ekspedisi JPLogistics dengan pemanfaatan teknologi yang dimiliki.

5) Returnability: Bansos Rastra pada titik distribusi telah melewati pemeriksaan kuantitas dan kualitas. Apabila Bansos Rastra tidak sesuai maka Perum BULOG Divre Kalbar akan menggantinya sesuai dengan kesepakatan dalam waktu selama 2 hari, namun pada wilayah yang tidak menerima Bansos setiap bulan akan mendapatkan pengganti pada periode berikutnya.

Analisis berikutnya yang dilakukan adalah analisis biaya dalam memenuhi kebutuhan pelanggan (supply chain driver). Setiap pendorong berpengaruh kepada beban pengeluaran, namun kalkulasi biaya tidak dilakukan mengingat keterbatasan informasi yang didapatkan. Adapun hasil analisis sebagai berikut:

1) Inventory: Strategi yang diterapkan Perum BULOG Divre Kalbar memiliki responsifitas yang sangat tinggi, ketika perintah untuk merealisasikan Bansos Rastra maka pengiriman langsung dapat dilakukan. Ini berdampak besarnya biaya untuk melakukan pembiayaan penyimpanan stok beras. Di sisi lain penerapan strategi sudah tepat dilakukan untuk Perum BULOG Divre Kalbar mengingat tugas-tugas Pemerintahan yang harus dijalankan.

2) Transportation: Transportasi yang digunakan untuk merealisasikan Bansos Rastra Perum BULOG
Divre Kalbar, Subdivre dan Kansilog hingga titik distribusi memanfaatkan truk (less than truckload) yang berkapasitas 7-8 ton. Tingginya biaya transportasi outbond pada supply chain Bansos Rastra dikarenakan penggunaan truk yang berkapasitas sedang dan harus menjangkau sebanyak 14 Kota dan Kabupaten wilayah Kalimantan Barat. Transportasi mendukung kinerja Perum BULOG di dalam menjalankan strategi yang lebih responsif terhadap permintaan.

3) Facility: Fasilitas yang dimiliki Perum BULOG Divre Kalbar membantu di dalam memaksimalkan penerapan strategi dan menjalankan fungsi yang diberikan Pemerintahan. Fasilitas yang ditawarkan berdekatan dengan masyarakat dengan pembagian wilayah kerja. Adapun fasilitas gudang yang dimiliki sebagai berikut:

TABEL II

GUDANG PERUM BULOG DIVRE KALBAR

\begin{tabular}{|l|l|l|l|l|} 
No & $\begin{array}{l}\text { Wilayah } \\
\text { Kerja }\end{array}$ & Kedudukan & Kompleks & $\begin{array}{l}\text { kapasitas } \\
\text { Gudang }\end{array}$ \\
\hline \multirow{2}{*}{1} & Divre Kalbar & Pontianak & GBB Wajo Hulu & 17.500 \\
\cline { 4 - 5 } 2 & $\begin{array}{l}\text { Subdivre } \\
\text { Singkawang }\end{array}$ & Singkawang & GBB Sei Raya & 14.000 \\
\cline { 4 - 5 } 3 & $\begin{array}{l}\text { Subdivre } \\
\text { Ketapang }\end{array}$ & Ketapang & GBB Prapakan Besi & 3.500 \\
\hline \multirow{2}{*}{4} & $\begin{array}{l}\text { Subdivre } \\
\text { Sintang }\end{array}$ & Sintang & GBB Mulia Baru & 1.000 \\
\hline \multirow{2}{*}{5} & $\begin{array}{l}\text { Kansilog } \\
\text { Sanggau }\end{array}$ & Sanggau & GBB & 1.000 \\
\hline 6 & $\begin{array}{l}\text { Kansilog } \\
\text { Putussibau }\end{array}$ & Putussibau & GBB & 1.000 \\
\hline
\end{tabular}

4) Information: Dalam menjalankan program Bansos Rastra, Mekanisme berbagi informasi dilakukan melalui media surat, telepon, fax, maupun koordinasi langsung antara Perum BULOG Divre Kalbar dan Pemerintah Daerah. Media tersebut digunakan untuk bertukar informasi terutama pihak yang terlibat secara langsung di dalam mendistribusikan Bansos Rastra. Pertukaran informasi tidak memerlukan biaya yang besar, dikarenakan tidak membutuhkan perangkat IT yang kompleks untuk bantuan operasional.

\section{Distribution Requirement Planning}

Penerapan DRP pada Perum BULOG Divre Kalbar dipengaruhi beberapa komponen diantara lain analisis Bill Of Distribution (BOD), analisis push dan pull, forecasting dan lot size. Kebutuhan informasi tambahan diantara lain demand, inventory yang dimiliki, dan lead time.

Analisis BOD atau struktur jaringan distribusi merupakan tahapan identifikasi sebuah sasaran distribusi pada Program Bansos Rastar. Adapun hasil analisis BOD seperti pada Gambar 5. 


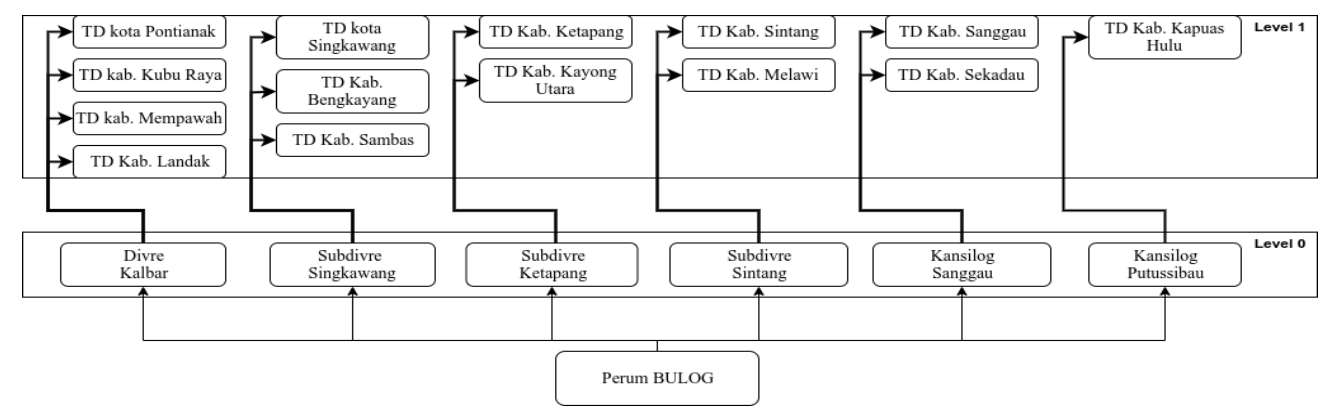

Gambar. 5 Analisis bill of distribution

Analisis sistem pengisian inventory pada supply chain Bansos Rastra terdiri dari sistem push (dorong) dan sistem pull (tarik). Analisis ini dilakukan agar mengetahui sistem yang tepat diberlakukan untuk Perum BULOG Divre Kalbar. Adapun hasil analisis sistem push dan pull terdapt pada Gambar 6.

Forecasting (Peramalan) digunakan untuk mengetahui perencanaan kebutuhan dari permintaan yang akan datang. Karakteristik permintaan Bansos Rastra (deterministik) sehingga perencanaan kebutuhan Bansos Rastra dapat dilakukan berdasarkan realisasi Bansos Rastra yang telah dilakukan. Sementara teknik lot size yang digunakan yaitu lot for lot. Teknik tersebut menentukan kuantitas Bansos Rastra sesuai dengan net requirement.

Setelah memahami komponen yang digunakan, selanjutnya melakukan kalkulasi para DRP worksheet. Metode DRP terdiri dari descriptive information dan time phased information. Adapun contoh DRP worksheet untuk Kota Pontianak terdapat pada Tabel 3.

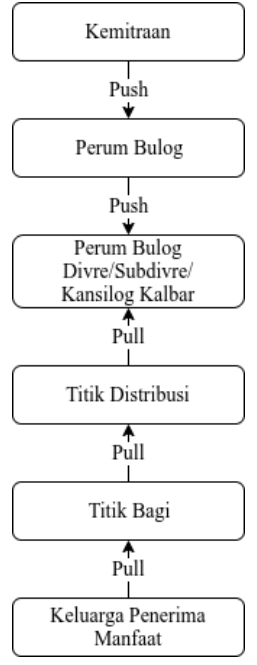

Gambar. 6 Analisis sistem push dan pull

TABEL III

DISTRIBUTION REQUIREMENT PLANNING WORKSHEET KOTA PONTIANAK

\begin{tabular}{|c|c|c|c|c|c|c|c|c|c|c|c|c|}
\hline Product & \multicolumn{2}{|c|}{ Bansos Rastra } & & & & & & & & & & \\
\hline Safety Stock: & \multicolumn{2}{|l|}{0} & \multicolumn{3}{|c|}{ Lead Time: } & \multicolumn{2}{|l|}{0,033} & & & & & \\
\hline \multirow[t]{3}{*}{ Order Quantity: } & \multicolumn{2}{|c|}{ Lot For Lot } & \multicolumn{3}{|c|}{ On Hand: } & \multicolumn{2}{|l|}{0} & & & & & \\
\hline & \multicolumn{12}{|c|}{ Period } \\
\hline & 1 & 2 & 3 & 4 & 5 & 6 & 7 & 8 & 9 & 10 & 11 & 12 \\
\hline Gross Requirement & $\begin{array}{l}153.3 \\
40 \\
\end{array}$ & $\begin{array}{l}153.3 \\
40\end{array}$ & $\begin{array}{l}153 . \\
340\end{array}$ & $\begin{array}{l}153 . \\
340\end{array}$ & $\begin{array}{l}153 . \\
340\end{array}$ & $\begin{array}{l}153 . \\
340\end{array}$ & $\begin{array}{l}153 . \\
340\end{array}$ & $\begin{array}{l}153.3 \\
40 \\
\end{array}$ & $\begin{array}{l}153 . \\
430\end{array}$ & 0 & 0 & 0 \\
\hline \multicolumn{13}{|l|}{ Intransit Receipt } \\
\hline Projected Available Balance & 0 & 0 & 0 & 0 & 0 & 0 & 0 & 0 & 0 & 0 & 0 & 0 \\
\hline Net Requirement & $\begin{array}{l}153.3 \\
40\end{array}$ & $\begin{array}{l}153.3 \\
40 \\
\end{array}$ & $\begin{array}{l}153 . \\
340\end{array}$ & $\begin{array}{l}153 . \\
340\end{array}$ & $\begin{array}{l}153 . \\
340\end{array}$ & $\begin{array}{l}153 . \\
340\end{array}$ & $\begin{array}{l}153 . \\
340\end{array}$ & $\begin{array}{l}153.3 \\
40\end{array}$ & $\begin{array}{l}153 . \\
430\end{array}$ & 0 & 0 & 0 \\
\hline Planned Order Receipt & $\begin{array}{l}53.3 \\
40 \\
\end{array}$ & $\begin{array}{l}153.3 \\
40 \\
\end{array}$ & $\begin{array}{l}153 . \\
340\end{array}$ & $\begin{array}{l}153 . \\
340\end{array}$ & $\begin{array}{l}153 . \\
340\end{array}$ & $\begin{array}{l}153 . \\
340 \\
\end{array}$ & $\begin{array}{l}153 . \\
340 \\
\end{array}$ & $\begin{array}{l}153.3 \\
40 \\
\end{array}$ & $\begin{array}{l}153 . \\
430 \\
\end{array}$ & 0 & 0 & 0 \\
\hline Planned Order Release & $\begin{array}{l}153.3 \\
40\end{array}$ & $\begin{array}{l}153.3 \\
40\end{array}$ & $\begin{array}{l}153 . \\
340\end{array}$ & $\begin{array}{l}153 . \\
340\end{array}$ & $\begin{array}{l}153 . \\
340\end{array}$ & $\begin{array}{l}153 . \\
340\end{array}$ & $\begin{array}{l}153 . \\
340\end{array}$ & $\begin{array}{l}153.3 \\
40\end{array}$ & $\begin{array}{l}153 . \\
430\end{array}$ & 0 & 0 & 0 \\
\hline
\end{tabular}

\section{Perancangan jaringan distribusi Bansos Rastra}

Desain distribusi Bansos Rastra merupakan sebuah sistem yang dibangun menggunakan metodologi System Development Lyfe Cycle (SDLC). Analisis dilakukan berorientasi pada objek terhadap konteks supply chain Bansos Rastra, analisis kebutuhan terhadap pelanggan dan metode Distribution Requirement Planning (DRP). Hasil analisis yang dilakukan menyesuaikan kebutuhan sistem distribusi Bansos Rastra untuk Perum BULOG Divre Kalbar. Setelah melakukan analisis, dilanjutkan dengan melakukan perancangan objek yang telah diidentifikasi. Perancangan dilakukan untuk mengkorelasikan objekobjek yang menjadi sebuah sistem desain jaringan supply chain Bansos Rastra. Objek akan diklasifikasikan menggunakan tool UML, objek kemudian akan 
digambarkan menggunakan class diagram yang berperan sebagai class dan relasi sebuah sistem.

Adapun parameter yang terdapat pada jaringan distribusi Bansos Rastra telah dilakukan analisis menghasilkan 20 parameter diantara lain Perum BULOG; Perum BULOG Divre Kalbar; Perum BULOG Subdivre; Perum BULOG Kansilog; Mitra Kerja Pengadaan; Perusahaan; Badan Usaha; Gapoktan MKP; Onfarm; Gapoktan OF; Kementerian Sosial; Surat Perintah; Tim Koordinasi; Titik Distribusi; Titik Bagi; Keluarga Penerima Manfaat; Delivery Order; Bahan Baku; Beras; Bansos Rastra.
Sementara parameter untuk melakukan analisis kebutuhan diantara lain response time; product availability, returnability; customer experience, order visibility, inventory; transportation; facilities; information dan supply chain network design. Kemudian. Adapun parameter untuk optimasi model distribusi diantara lain distribution requirement planning; lead time; order quantity; onhand balance; forecasting; lot size.

Seluruh objek kemudian dikorelasikan menjadi sebuah model jaringan distribusi Bansos Rastra sesuai dengan kebutuhan untuk Perum BULOG Divre Kalbar. Model tersebut divisualisasikan dalam bentuk class diagram seperti pada Gambar 7.

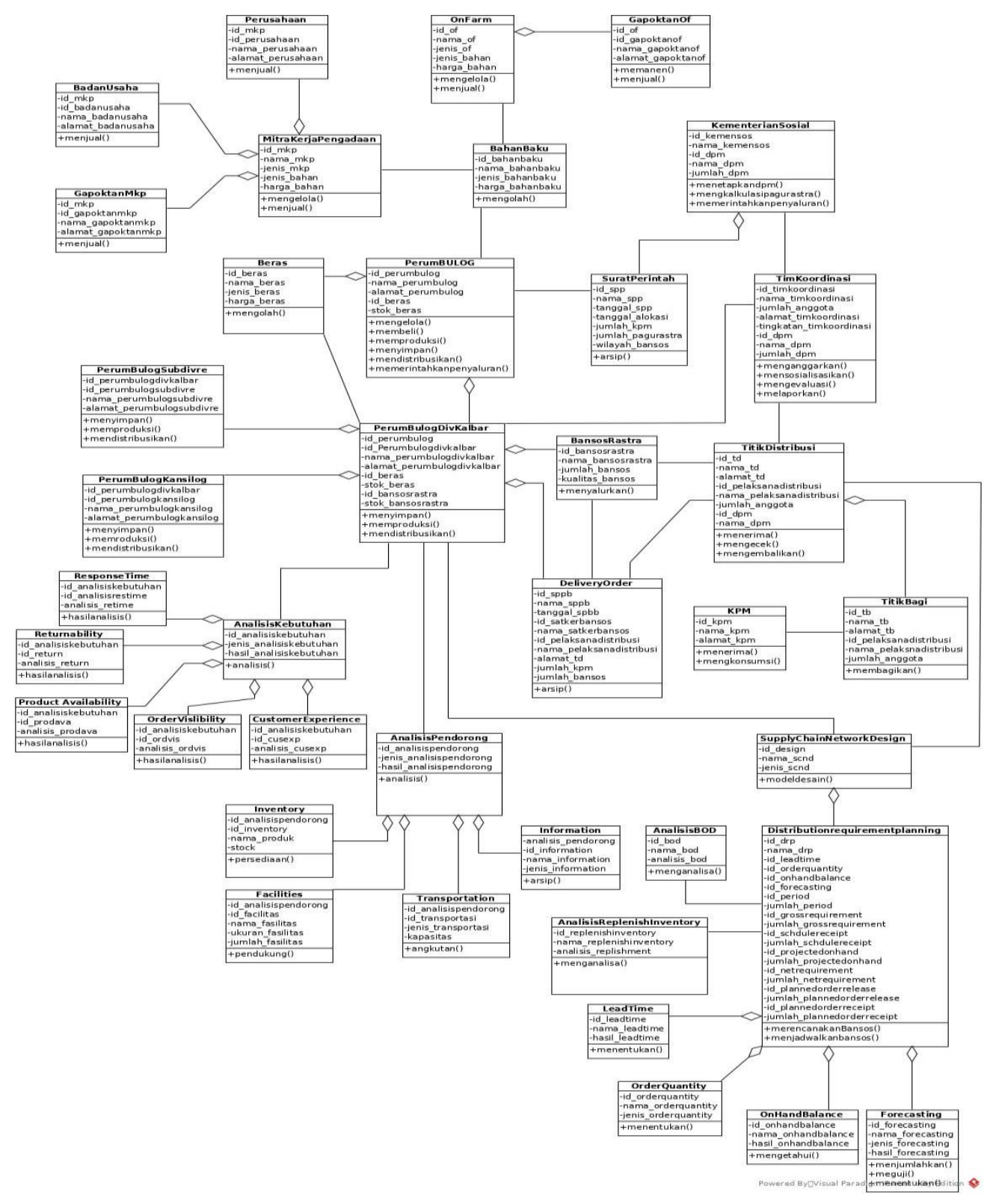

Gambar. 7 Class diagram model jaringan distribusi bansos rastra 


\section{E. Implementasi Desain Distribusi}

Perum BULOG Divre Kalbar memiliki fasilitas dengan total 10 Gudang yang terletak berdekatan untuk setiap Titik Distribusi yang terdapat pada 14 Kota dan Kabupaten wilayah Kalimantan Barat. Hasil desain jaringan distribusi Bansos Rastra pada Perum BULOG Divre Kalbar berupa allocation capacity. Metode Distribution Requirement Planning (DRP) yang diterapkan pada Perum BULOG Divre Kalbar mengoptimalkan kebutuhan inventory Sehingga model jaringan distribusi yang dibangun membantu Perum BULOG Divre Kalbar memahami kebutuhan alokasi Bansos Rastra pada setiap Titik Distribusi dan mengantisipasi terjadinya kekosongan stok Bansos Rastra yang ada pada Gudang BULOG.Hasil desain distribusi diilustrasikan pada Gambar 8.

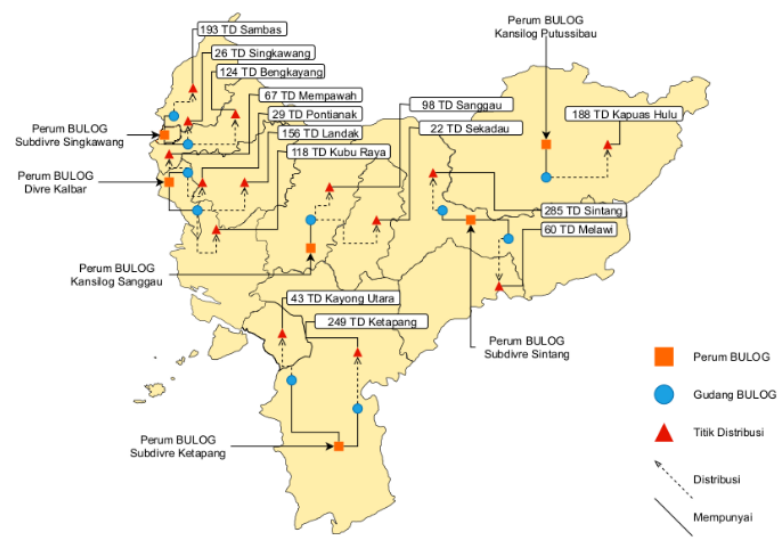

Gambar. 8 Desain jaringan distribusi perum BULOG divre Kalbar

Penerapan hasil dari desain distribusi menggunakan Distribution Requirement Planning (DRP) dalam rangka mengoptimalkan kebutuhan inventory pada Titik Distribusi. Adapun kebutuhan untuk Bansos Rastra terdapat pada Tabel 4 sebagai berikut.

TABEL IV

DESAIN DISTRIBUSi BANSOS RASTRA METODE DRP

\begin{tabular}{|l|l|l|l|}
\hline No & Nama Wilayah & $\begin{array}{l}\text { Frekuens } \\
\mathbf{i} \\
\text { Distribus } \\
\text { i }\end{array}$ & $\begin{array}{l}\text { Kebutuhan } \\
\text { Bansos } \\
\text { Rastra }\end{array}$ \\
\hline 1 & Kota Pontianak & 9 & 1.380 .150 \\
\hline 2 & Kab. Kubu Raya & 12 & 2.834 .760 \\
\hline 3 & Kab. Mempawah & 12 & 1.306 .920 \\
\hline 4 & Kab. Landak & 12 & 3.075 .120 \\
\hline 5 & Kota Singkawang & 10 & 706.100 \\
\hline 6 & Kab. Bengkayang & 12 & 1.078 .440 \\
\hline 7 & Kab. Sambas & 12 & 3.059 .160 \\
\hline 8 & Kab. Ketapang & 12 & 3.560 .610 \\
\hline 9 & Kab. Kayong Utara & 12 & 781.320 \\
\hline 10 & Kab. Sintang & 12 & 2.716 .080 \\
\hline 11 & Kab. Melawi & 12 & 1.616 .220 \\
\hline 12 & Kab. Sanggau & 12 & 1.277 .340 \\
\hline 13 & Kab. Sekadau & 12 & 992.760 \\
\hline 14 & Kab. Kapuas Hulu & 12 & 1.539 .480 \\
\hline
\end{tabular}

\section{Pengujian}

Hasil pengujian yang dilakukan menggunakan metode User Acceptance Test (UAT) dengan teknik in-depth interview. Pengujian dilakukan kepada pihak Perum BULOG Divre Kalbar. Pengujian model ini dilakukan untuk memvalidasi apakah hasil desain yang telah dirancang sesuai dengan kebutuhan Bansos Rastra. Adapun hasil pengujian yang telah dilakukan sebagai berikut:

\section{A. Tingkat Pemahaman}

Memahami konsep dari supply chain Bansos Rastra dan telah sesuai dengan aktivitas Bansos Rastra yang diterapkan oleh Perum BULOG Divre Kalbar, memahami metode Distribution Requirement Planning (DRP) yang digunakan pada penelitian ini dan memahami secara umum model sistem desain distribusi untuk Program Bansos Rastra.

\section{B. Efisiensi}

perencanaan pada Bansos Rastra dapat membantu dalam hal efisiensi dan perusahaan seperti Perum BULOG Divre Kalbar pastinya memiliki perencanaan.

\section{Utilitas}

Hasil dari penelitian yang dapat dikatakan bermanfaat meskipun membutuhkan pemahaman lebih lanjut dan perlunya perbaikan agar penelitian sesuai dengan kebutuhan dari Perum BULOG Divre Kalbar dan penerapan model desain jaringan distribusi memiliki keunggulan dengan sistem perencanaan oleh Perum BULOG Divre Kalbar dapat menjadi pertimbangan oleh narasumber dan akan melihat lebih lanjut.

\section{Kesiapan}

Model desain distribusi menggunakan metode Distribution Requirement Planning (DRP) dapat dijalankan untuk Perum BULOG Divre Kalbar serta Perum BULOG Subdivre dan Perum BULOG Kansilog.

\section{KESIMPULAN}

Penelitian ini meliputi empat tahapan meliputi identifikasi proses supply chain Bansos Rastra; manganalisis kebutuhan Bansos Rastra; merancang dan memvalidasi jaringan distribusi Bansos Rastra. Hasil identifikasi supply chain Bansos Rastra meliputi kemitraan - Perum BULOG - Perum BULOG Divre Kalbar - Titik Distribusi - Titik Bagi - Keluarga Penerima Manfaat (KPM). Pendekatan yang dilakukan menggunakan SDLC hingga tahap perancangan. Hasil analisis dilakukan berorientasi objek untuk desain jaringan distribusi Bansos Rastra. Berdasarkan studi pustaka yang telah dilakukan terdapat 20 objek pada sistem Bansos Rastra yang dibangun dari anggota langsung dan tidak langsung. Pada konsep jaringan distribusi terdapat 12 objek dan konsep DRP 7 objek. Seluruh objek yang telah teridentifikasi akan dikorelasikan menggunakan class diagram. Pada 
penelitian ini sistem yang telah dirancang dilakukan validasi menggunakan teknik UAT, hasilnya model desain jaringan distribusi dapat diterapkan untuk Perum BULOG Divre Kalbar.

\section{REFERENSI}

[1] Straka, Martin, and Dusan Malindzak. 2010. Classification Of Distribution Networks. Total Logistic Management (3): 79-86.

[2] Thomopoulos, N. T. (2016). Elements of Manufacturing, Distribution and Logistics. Chicago: Springer International Publishing.

[3] Waters, D. (2003). Global Logistics and Distribution Planning: Strategies For Management. $4^{\text {th }}$ Edition. London: Kogan Page Limited.

[4] Rushton, A., Croucher, P., and Baker, P. (2014). The Handbook Of Logistics and MassachusettsDistribution Management. $5^{\text {th }}$ Edition. London, Philadelphia, New Delhi: Kogan Page Limited.

[5] Ross, D. F. (2015). Distribution Planning and Control: managing in the era of supply chain management. $3^{\text {th }}$ Edition. Chicago: Springer Science+Business Media.

[6] Inpres RI [Intruksi Presiden Republik Indonesia]. (2015) Intruksi Presiden Republik Indonesia No 5 Tentang kebijakan pengadaan gabah/beras dan penyaluran beras oleh pemerintah.
[7] Chopra, S., and Meindl, P. (2007). Supply Chain Management: Strategy, Planning, and Operation. $3^{\text {th }}$ Edition. New Jersey: Pearson Education, Inc.

[8] Nickerson, R. C. (2000). Business and Information Systems. $2^{\text {nd }}$ Edition. Addison Wesley.

[9] Date, C. J. (2004). An Introduction to Database Systems. $8^{\text {th }}$ Edition. Pearson Education, Inc.

[10] Kendall, K and Kendall, J. E. (2014). Systems Analysis \& Design. $9^{\text {th }}$ Edition. USA: Pearson Education, Inc.

[11] Dennis, A., Wixom, B. H., and Tegarden, D. (2012). Systems Analysis and Design with UML Version 2.0 An Object-Oriented Approach. $4^{\text {th }}$ Edition. USA: John Wiley and Sons, Inc.

[12] Booch, G., Rumbaugh, J., and Jacobson, I. (2005). The Unified Modelling Language User Guide. $2^{\text {nd }}$ Edition. Massachusetts: Pearson Education, Inc

[13] Perry, W. E. (2006). Effective Method For Software Testing Includes Complete Guidelines and Checklists. $3^{\text {rd }}$ Edition. Indiana: Wiley Publishing, Inc

[14] Ripanti, E. F. (2016). A Framework to Design Reverse Logistics Operation based on Circular Economy Values. $\mathrm{PhD}$ Thesis, Cranfield University.

[15] Hevner, A. R., March, S. T., Park, J., and Ram, S. (2004). Design Science In Information Systems Research. MIS quarterly, 28(1), 75-105. 